\title{
Treatment Outcome, Cognitive Function and Psychopathology in Methamphetamine Users Compared to Other Substance Users
}

\section{Felicia Kamp}

Psychotherapy University Hospital Munich

\section{Nina Behle}

Psychotherapy University Hospital Munich

\section{Lisa Proebstl}

Psychotherapy University Hospital Munich

\section{Laura Hager}

Psychotherapy University Hospital Munich

\section{Marlies Riebschläger}

MEDIAN Clinic Mecklenburg, Blumenstraße 3, 19217 Vitense

\section{Maik Schacht-Jablonowsky}

MEDIAN Clinic Mecklenburg, Blumenstraße 3, 19217 Vitense

\section{Willem Hamdorf}

MEDIAN Clinic Mecklenburg, Blumenstraße 3, 19217 Vitense

\section{Steffi Neumann}

MEDIAN Clinic Mecklenburg, Blumenstraße 3, 19217 Vitense

Daniela Krause ( $\square$ Daniela.Krause@med.uni-muenchen.de)

Psychotherapy University Hospital Munich

\section{Kirsi Manz}

Institute for Medical Information Processing, Biometry and Epidemiology (IBE), Faculty of Medicine, LMU Munich

\section{Andreas G. Franke}

University of Applied Labour Studies of the Federal Employment Agency (UALS), Seckenheimer Landstr. 16, 68163 Mannheim

\section{Gabi Koller}

Psychotherapy University Hospital Munich

\section{Michael Soyka}

Psychotherapy University Hospital Munich

\section{Research Article}


Keywords: Treatment outcome, cognitive function, psychopathology, methamphetamine users, substance users, United Nations

Posted Date: October 27th, 2021

DOI: https://doi.org/10.21203/rs.3.rs-981861/v1

License: (1) This work is licensed under a Creative Commons Attribution 4.0 International License. Read Full License 


\section{Abstract}

Background: There is an increasing demand of treatment options for methamphetamine users. The present study evaluates differences between methamphetamine users and users of other substances with respect to cognitive function and psychopathology and possible correlates of treatment outcome.

Method: 110 subjects were recruited for an observational longitudinal study from a German inpatient addiction treatment center: 55 patients with methamphetamine dependence and 55 patients with dependence of other substances (OS group). Groups were examined at beginning (baseline) and end of treatment (after six months) with regard to treatment retention, craving, cognitive functioning, psychosocial resources, personality traits, and psychiatric symptoms.

Results: A total drop-out rate of $40 \%$ was observed without significant differences. At baseline, Methamphetamine-group subjects had significantly lower intelligence quotient, less years of education, poorer working speed and lower working accuracy and cannabinoid and cocaine use compared to OSgroup. Methamphetamine-group subjects showed a significantly lower score of conscientiousness, psychiatric symptoms than subjects from the OS-group. Both groups showed a reduction of craving and depressive symptoms and an improvement of working speed and working accuracy after treatment.

Conclusions: There are differences between methamphetamine users and users of other drugs, but not with regard to the effectiveness of treatment in this inpatient setting.

\section{Introduction}

The United Nations estimate that about 27 million people worldwide regularly abuse amphetamine-type stimulants (ATS) ${ }^{1}$. Especially the rising number of people using methamphetamine causes growing concern ${ }^{2}$. Accordingly, figures for methamphetamine users in drug rehabilitation is increasing worldwide and there is a growing need of evidence-based treatment options for methamphetamine users ${ }^{3}$. To date, evidence-based research on the efficacy of treatment programs for methamphetamine users is still limited ${ }^{4}$ and the question arises whether established treatment methods for individuals using other substances can be effective for the treatment of methamphetamine dependence as well. This question is important, since -until a few years ago- methamphetamine use played a minor role in German substance treatment services and therefore most methamphetamine users are treated in hospitals or institutions, that still have limited experience with methamphetamine use, but extensive experience with other substance use disorders as for example alcohol, opioids, amphetamine, or cocaine. However, representative studies comparing the characteristics of methamphetamine users to users of other substances are limited. A study based on expert interviews and focus groups to examine the characteristics of methamphetamine consumers showed that they differ from users of other stimulants for example in higher levels of dissocial behavioral (e.g. aggressiveness, impulsiveness, egoism or irritability) as well as a low awareness of their situation, emotional instability, unreliability and many comorbidities ${ }^{5}$. The authors also reported that treatment of methamphetamine users is substantially 
affected by their comorbidities and stated, that the provided rehabilitation for methamphetamine users in Germany is inadequate, resulting in a need to adapt the treatment concepts for this group ${ }^{5}$. Another study also showed that methamphetamine use seems to be associated with co-occuring substance use and mental illness ${ }^{6}$. In addition, there are also data indicating that methamphetamine use may lead to neural damage which is commonly associated with persistent cognitive impairment, including deficits in attention, memory and executive function ${ }^{7}$. These results are in line with other studies also demonstrating that methamphetamine users may differ from other substance users with respect to cognitive function ${ }^{8,9}$. This may be of relevance for treatment outcome, since for example Bernhardt et al. noted correlations between outcome in methamphetamine treatment and recovery of cognitive impairment ${ }^{10}$.

Another study found an association between a low level of social support and methamphetamine dependence ${ }^{11}$. However, the authors also found an association between moderately (and not distinct) pronounced personality factors (agreeableness, neuroticism, extraversion, conscientiousness and openness) and methamphetamine use ${ }^{11}$.

These studies have been mostly of exploratory nature and were investigating exclusively methamphetamine users, but without direct comparison to other drug users. Therefore, the present study aims to examine methamphetamine users' characteristics in comparison with users of other drugs. For this analysis, we focus on factors such as cognition, personality traits, comorbidities, psychiatric symptoms and psychosocial resources and their implication on treatment outcome. Again, there is a lack of studies investigating the treatment outcome of methamphetamine users in existing treatment services, which makes it difficult to deduce specific hypotheses. Based on this limited previous research, one may assume that methamphetamine users have more neuropsychiatric symptoms compared to users of other substances. Specifically, a higher rate of comorbid psychiatric symptoms and disorders, a lower level of cognitive functioning and limited psychosocial resources and finally lower retention rate in treatment in methamphetamine users can be postulated. This exploratory study focuses on these possible differences in primary methamphetamine users compared to users of other substances.

\section{Results}

\section{Participants' flow and treatment completion}

A total of 110 participants (55 in each group, 89 men and 21 women) with a mean age of 30.95 years $(S D=6.65)$ were included in the first assessment at T0. There were no statistically significant differences in age (30.0 vs. 32.0 years, $p=.12)$ or gender distribution ( $76.4 \%$ vs. $85.5 \%$ males, $p=.23)$ between Methamphetamine- and OS-groups. Out of this original sample, 18 subjects refused to take part in further assessments after T0 and 55 subjects ( 27 from Methamphetamine-, 28 from OS-group) participated again in the second measurement $T 1$ with a mean age of 30.0 years $(S D=6.43)$. Again, the majority of $T 1$ 
subjects was male ( 45 men, 10 women) and there was no significant difference in gender distribution ( $p=$ $.50)$.

From the baseline sample, 66 subjects (60\%) completed the treatment while 44 individuals (40\%) dropped-out of treatment. Comparison of the Methamphetamine-group and the OS-group revealed no significant difference in drop-out rates $(36.4 \%$ vs. $43.6 \%, p=0.44)$. There was neither a significant difference in age $(p=.19)$ nor in gender distribution $(p=0.84)$ between drop-outs and completers.

The reasons for drop-out were as follows: The most common reason for treatment drop-out was at own request (42.2\%), followed by violation of institution rules $(26.7 \%)$, unreported relapse during treatment $(24.4 \%)$ and transfer to another treatment center (6.7\%). There was no significant association in the reasons for drop-out between Methamphetamine and OS-group $(p=.21)$.

Participants remained in treatment for a mean time of 147 days $(S D=68)$. There was a trend towards a longer treatment retention in the Methamphetamine-group compared to OS-group, but this difference failed to reach statistical significance $(159(S D=60)$ vs. 135 days $(S D=73), p=.07)$. The OS group attended a slightly higher mean number of group sessions (OS: 103 (SD=57); Methamphetamine: 87 $(S D=35), p=.07)$, while the Methamphetamine-group had a slightly higher mean number of individual therapy sessions (Methamphetamine: $27(S D=18)$; OS $22(S D=13), p=.08)$. However, both differences were not statistically significant. A mean treatment duration of 93 days $(S D=57)$ was found among the patients dropping out of treatment.

\section{Baseline comparisons of Methamphetamine and OS-group characteristics}

Methamphetamine-group subjects had less years of education than OS-group subjects $(p=.048)$ and showed a significantly lower mean intelligent quotient (Raven`s IQ=93.7) at baseline than the OSindividuals $(\mathrm{IQ}=100.1, \mathrm{p}=.02$, see also Table 3$)$. Methamphetamine-group participants also performed poorer on both measures of the cognitive test battery Cognitrone, resulting in a significantly lower working speed $(p=.002)$ and working accuracy $(p=.03)$ compared to OS-subjects. Methamphetamineand OS- subjects showed no significant differences with respect to employment $(p=.19)$ or partnership during the last six months prior to admission $(p=.46)$. 
Table 1

phases of the therapeutic treatment concept

\begin{tabular}{|c|c|c|}
\hline $\begin{array}{l}\text { Therapy } \\
\text { phase }\end{array}$ & Content and therapy frequency & Duration \\
\hline Admission & Checking the entry requirements, e.g. clean status & $\begin{array}{l}\text { Admission } \\
\text { day }\end{array}$ \\
\hline $\begin{array}{l}\text { Entry } \\
\text { phase }\end{array}$ & $\begin{array}{l}\text { Diagnostics, self reflection, strengthen and increasing motivation, } \\
\text { defining therapy goals, treatment planning }\end{array}$ & 2 weeks \\
\hline $\begin{array}{l}\text { Main } \\
\text { phase }\end{array}$ & 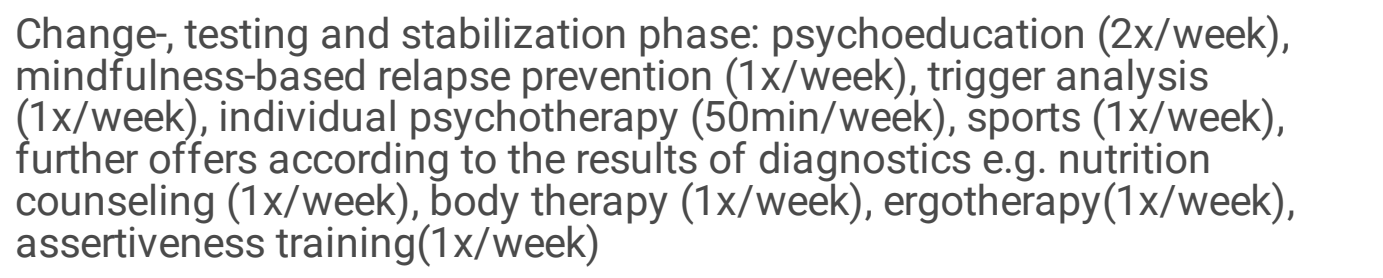 & 22 weeks \\
\hline Dismissal & $\begin{array}{l}\text { Follow-up plan, relapse prevention, arrangement of further contacts with } \\
\text { addiction counseling center, doctors and psychotherapists, clarified social } \\
\text { situation, e.g. contact to job center and clarified housing situation }\end{array}$ & 2 weeks \\
\hline
\end{tabular}


Table 2

Study Instruments

Instrument Description

21-question multiple-choice self-report inventory measuring the

Assessment

Becks Depression Inventory-II (BDI-

II) 22

Cognitrone ${ }^{23}$

severity of depression. Raw scores were used for analyses.

T0, T1

T0, T1

Computer administered Test of cognitive working speed and working accuracy (comparisons of geometrical figures). Scores were standardized into T-values according to test norms.

Documentation standards III for the evaluation of the treatment of dependent individuals 24
Hamilton

Depressive Rating Scale (HAMD) ${ }^{25}$
Defined items to assess substance use and related factors (e.g. years of substance use, age at use onset, number of withdrawals)
T0
Clinician-administered depression assessment scale, containing 17 items of symptoms of depression. Time period: past week. Assessed as a semi structured interview. Raw scores were used for analyses.

\section{Inventory of personal psychosocial resources ${ }^{26}$}

T0, T1

T0, T1

Self-report questionnaire measuring psychosocial resources in the past and at present based on different scales, e.g. relationship, friends, financial and work situation. A total raw score of all scales measuring the present situation was built and used for analyses.

\section{Mannheimer Craving Scale} 27

NEO-Five-FactorInventory (NEOFFI) ${ }^{28}$
Self-report questionnaire with 12 multiple choice items and 4 additional items measuring Craving within the last seven days. Raw scores from the main 12 items were used for analyses.
T0, T1

Self-report questionnaire with 60 items for the measurement of

T0 the so-called "big five" personality traits (neuroticism, extraversion, openness, agreeableness, consciousness). Scores were standardized into T-values according to test norms.
Raven's Standard Progressive Matrices ${ }^{29}$
Nonverbal intelligence test, Computer version. Scores were standardized into IQ values according to test norms
T0

T0
Structured

Clinical Interview for DSM-IV Axis I 30
Diagnostic structured interview to determine the presence of DSM-IV Axis I disorders 
Symptom

Checklist 90-R

$(\mathrm{SCL}-90 \mathrm{R})^{31}$
Self-report questionnaire assessing symptoms of psychopathology on different scales. For this study two scales were use: intensity of depressive symptoms scale and "Positive Symptom Distress Index" (PSDI), a measure of intensity of present symptoms. Scores of both scales were standardized into T-values according to test norms.
Wender Utah Rating Scale short Version (Wursk) ${ }^{32}$
Short version ( 25 items including 4 control items) of a self-report T0 questionnaire assessing retrogradely childhood symptoms of attention deficit hyperactivity disorder. Raw Scores were built from the 21 core items and used for analyses. 
Table 3

Comparison between MA- and OS-group at Baseline T0

\begin{tabular}{|c|c|c|c|}
\hline & MA-group & OS-group & $p$ \\
\hline $\mathbf{N}$ & 55 & 55 & \\
\hline Male & $42(76.4 \%)$ & 47 (85.5\%) & $p=.23$ \\
\hline Age & $30.0( \pm 5.3)$ & $32.0( \pm 7.7)$ & $p=.12$ \\
\hline $\begin{array}{l}\text { Number of withdrawals } \\
(\mathrm{n}=48)\end{array}$ & $3.0( \pm 4.1)$ & $3.0( \pm 4.1)$ & $p=.98$ \\
\hline $\begin{array}{l}\text { Raven's IQ } \\
(M A n=50,0 S n=54)\end{array}$ & $93.7( \pm 13.5)$ & $100.1( \pm 13.6)$ & $p=.02$ \\
\hline $\begin{array}{l}\text { Cognitrone working speed } \\
(M A n=53,0 S n=54)\end{array}$ & $49.1( \pm 8.0)$ & $54.3( \pm 9.0)$ & $p=.002$ \\
\hline $\begin{array}{l}\text { Cognitrone accuracy } \\
(M A n=53, \text { OS } n=54 \text { ) }\end{array}$ & $43.0( \pm 8.9)$ & $47.1( \pm 9.8)$ & $p=.03$ \\
\hline Personality factors & $n=37$ & $n=42$ & \\
\hline Neuroticism & $22.8( \pm 6.7)$ & $25.1( \pm 9.7)$ & $p=.24$ \\
\hline Extraversion & $25.0( \pm 6.0)$ & $25.2( \pm 7.5)$ & $\mathrm{p}=.89$ \\
\hline Openness & $26.3( \pm 5.6)$ & $28.6( \pm 6.7)$ & $p=.11$ \\
\hline Agreeableness & $26.6( \pm 4.2)$ & $27.9( \pm 6.8)$ & $p=.33$ \\
\hline Conscientiousness & $29.0( \pm 5.6)$ & $31.9( \pm 6.6)$ & $p=.04$ \\
\hline $\begin{array}{l}\text { BDI-II Score } \\
(M A n=42, \text { OS } n=54)\end{array}$ & $13.6( \pm 10.8)$ & $16.8( \pm 11.3)$ & $p=.17$ \\
\hline $\begin{array}{l}\text { HAMD Score } \\
\text { (MA n=46, OS n=42) }\end{array}$ & $5.3( \pm 4.8)$ & $8.3( \pm 7.9)$ & $p=.04$ \\
\hline $\begin{array}{l}\text { SCL-PSDI Score } \\
(\text { MA n=39, OS n=40) }\end{array}$ & $53.5( \pm 11.1)$ & $59.3( \pm 10.1)$ & $p=.02$ \\
\hline
\end{tabular}

Data displays means and standard deviations $( \pm$ ) or number of participants (education and employment); $\mathrm{MA}=$ methamphetamine, $\mathrm{OS}=$ other substances; different $\mathrm{n}$ result from missing values; BDI-II= Becks Depression Inventory-II; HAMD= Hamilton Depressive Rating Scale; $S C L=$ Symptom Checklist; Wursk= Wender Utah Rating Scale -short Version 


\begin{tabular}{|c|c|c|c|}
\hline & MA-group & OS-group & $p$ \\
\hline Wursk Score & $n=36$ & $\mathrm{n}=40$ & $p=.56$ \\
\hline$(M A n=36,0 S n=40)$ & $28.6( \pm 16.7)$ & $30.8( \pm 15.1)$ & \\
\hline Craving & $13.9( \pm 9.5)$ & $14.2( \pm 8.0)$ & $\mathrm{p}=.87$ \\
\hline \multicolumn{4}{|l|}{$(M A n=39$, OS $n=40)$} \\
\hline Years of education & $n=52$ & $n=50$ & $p=.048$ \\
\hline$\leq 9$ years & 35 & 24 & \\
\hline$\geq 10$ years & 17 & 26 & \\
\hline Employment & $\mathrm{n}=51$ & $n=48$ & $\mathrm{p}=.19$ \\
\hline Unemployed & 43 & 33 & \\
\hline Employed & 4 & 7 & \\
\hline Other (e.g. retiree) & 4 & 8 & \\
\hline \multirow[t]{2}{*}{ Ever injected } & $n=49$ & $n=40$ & $p=.75$ \\
\hline & 7 & 4 & \\
\hline \multicolumn{4}{|c|}{$\begin{array}{l}\text { Data displays means and standard deviations }( \pm) \text { or number of participants (education and } \\
\text { employment); MA= methamphetamine, OS= other substances; different } n \text { result from missing values, } \\
\text { BDI-II= Becks Depression Inventory-II; HAMD = Hamilton Depressive Rating Scale; SCL= Symptom } \\
\text { Checklist; Wursk= Wender Utah Rating Scale -short Version }\end{array}$} \\
\hline
\end{tabular}

Participants from the Methamphetamine-group showed a significantly lower score of the personality trait conscientiousness (measured by the NEO-Five-Factor-Inventory) compared with subjects from the OSgroup $(p=.04)$. No other personality traits differed significantly between both groups. The OS group showed significantly higher Hamilton Depressive Rating Scale (HAMD) $(p=.04)$ and Symptom Checklist $(\mathrm{SCL})$ depression $(p=.03)$ - but not Beck Depression Inventory-II (BDI- II) $(p=.17)$ - mean scores at treatment begin than the Methamphetamine-group. The OS-group also had a higher mean score of the SCL "Positive Symptom Distress Index" (PSDI), a measure of intensity of present symptoms, compared to the Methamphetamine-group $(p=.02)$. There were no statistically significant differences in Attention Deficit Hyperactivity Disorder (ADHD) scores $(p=.56)$, craving $(p=.87)$ or psychosocial resources $(p=.69)$ at baseline.

As explained, Methamphetamine-group subjects may have had a history of other drug use, but methamphetamine had to be the prior substance. The majority of all subjects also used cannabinoids, but the number of cannabinoid users was significantly higher in the OS-group than in the Methamphetamine-group $(p=.04)$. The OS-group also included a significantly higher number of individuals that used cocaine $(p=.001)$, while there were no differences in the use of other substances. 
There was no significant difference between groups concerning the number of previous substance use treatments $(p=.98)$

Regarding the number of comorbid psychiatric diagnoses (measured by ICD-10), a significantly higher rate in anxiety disorders $(p=.03)$ and somatoform disorders $(p<.0001)$ was found in Methamphetaminegroup patients, while there was a higher rate of psychotic disorders in OS- group participants $(p=.04$, see Table 4).

Table 4

Number of comorbid diagnoses

\begin{tabular}{|llll|}
\hline & $\begin{array}{l}\text { MA group } \\
\mathbf{n}=\mathbf{5 4}\end{array}$ & $\begin{array}{l}\text { OS group } \\
\mathrm{n}=\mathbf{5 5}\end{array}$ & $\boldsymbol{p}$ \\
\hline Depression & 11 & 15 & .40 \\
\hline Anxiety disorder & 5 & 0 & .03 \\
\hline Eating disorder & 0 & 2 & .49 \\
\hline $\begin{array}{l}\text { Obsessive-compulsive } \\
\text { disorder }\end{array}$ & 0 & 0 & - \\
\hline $\begin{array}{l}\text { Posttraumatic stress } \\
\text { disorder }\end{array}$ & 15 & 12 & .47 \\
\hline $\begin{array}{l}\text { Personality disorder } \\
\text { ADHD }\end{array}$ & 11 & & .96 \\
\hline $\begin{array}{l}\text { Psychotic disorder } \\
\text { Somatoform disorder }\end{array}$ & 6 & 7 & .80 \\
\hline $\begin{array}{l}\text { Annotation: Data displays number of participants diagnosed with the respective comorbidity. MA= } \\
\text { methamphetamine, OS= other substances, ADHD= Attention deficit and hyperactivity disorder. }\end{array}$ \\
\hline
\end{tabular}

\section{Comparisons of groups over time}

Mixed ANOVAs were used to compare the cognitive functioning over time and between groups. The working speed significantly improved from T0 to T1 in both groups $(p<.001$, see also Table 5$)$ and there was a significant group effect for both measurements, showing a better performance in the OS- than in the Methamphetamine group in working speed $(p<.001$, see figure 2$)$. There was no interaction effect $(p=$ .94). Regarding working accuracy, there also was a significant improvement of performance over time in both groups $(\mathrm{p}<.001)$. The OS-group showed a higher working accuracy at both times, but this effect was not statistically significant $(p=.43)$. Again, there was no interaction effect $(p=.79$, see figure 1$)$. Both 
groups showed a significant reduction of the intensity of psychiatric burden, as measured by the SCL-90R PSDI score, over time $(p<.001)$. The OS-group showed a greater decrease than the Methamphetaminegroup (see figure 2), but the interaction effect failed statistical significance $(p=.07)$. The groups did no longer differ significantly over time $(p=.29)$. SCL-90-R depression scores $(p<.001)$ and HAMD depression scores $(p=.001)$ significantly decreased over time in both groups. However, taking baseline and T1 assessment together, the difference between OS- and Methamphetamine-group was no longer significant (SCL depression score: $p=.09 ;$ HAMD: $p=.09$ ). Again, no interaction effects were found (SCL depression score: $p=.97$; HAMD: $p=.66$, see figure 3 ). Analyzing the BDI-II depression scores also revealed a significant effect of time, showing a reduction of depression scores from start to end of treatment $(p<$ $.001)$, but without interaction ( $p=.81)$ or group effect $(p=.56)$. Similar results were seen regarding craving scores: we found a significant reduction over time $(p<.001)$, without interaction $(p=.94)$, and without group effect $(p=.86)$. We found a significant increase of psychosocial resources over time $(p=.048)$, but again, no significant differences between both groups $(p=.99)$ and no interaction effect $(p=.71)$ 
Table 5

Comparison over time and between groups (ANOVA results)

\begin{tabular}{|c|c|c|c|c|c|c|}
\hline & & MA-group & $\mathbf{n}$ & OS-group & n & $\mathrm{p}$ \\
\hline \multirow[t]{3}{*}{$\mathrm{BDI}$} & TO & $15.31( \pm 11.55)$ & 26 & $16.36( \pm 12.39)$ & \multirow[t]{3}{*}{33} & $p_{\text {time }}{ }^{* \star}$ \\
\hline & $\mathrm{T} 1$ & $7.27( \pm 7.20)$ & & $8.97( \pm 8.98)$ & & \\
\hline & & & & & & $p_{\text {time }} \mathrm{x}_{\text {group }}{ }^{\text {n.s }}$ \\
\hline \multirow{4}{*}{$\begin{array}{l}\text { Cognitrone } \\
\text { accuracy }\end{array}$} & TO & $43.62( \pm 7.84)$ & 26 & $44.93( \pm 9.85)$ & \multirow[t]{4}{*}{28} & $p_{\text {time }}{ }^{\star \star \star}$ \\
\hline & & & & & & $p_{\text {group n.s. }}$ \\
\hline & $\mathrm{T} 1$ & $50.50( \pm 8.63)$ & & $52.54( \pm 10.16)$ & & \\
\hline & & & & & & $p_{\text {time }} \mathrm{x}_{\text {group }}$ \\
\hline \multirow{4}{*}{$\begin{array}{l}\text { Cognitrone } \\
\text { Speed }\end{array}$} & TO & $48.81( \pm 7.68)$ & 26 & $57.18( \pm 9.05)$ & \multirow[t]{4}{*}{28} & $p_{\text {time }}{ }^{\star \star \star}$ \\
\hline & & & & & & $p_{\text {qroup } * \star *}$ \\
\hline & $\mathrm{T} 1$ & $54.08( \pm 10.04)$ & & $62.61( \pm 10.88)$ & & \\
\hline & & & & & & $p_{\text {time }} \mathrm{x}_{\text {group }}{ }^{\mathrm{n} . \mathrm{s}}$ \\
\hline \multirow[t]{3}{*}{ HAMD } & TO & $6.52( \pm 5.36)$ & 25 & $9.59( \pm 9.14)$ & \multirow[t]{3}{*}{27} & 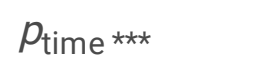 \\
\hline & $\mathrm{T} 1$ & $3.60( \pm 4.77)$ & & $5.81( \pm 5.98)$ & & $p_{\text {group n.s. }}$ \\
\hline & & & & & & $p_{\text {time }} \mathrm{x}_{\text {group }}{ }^{\mathrm{n} . \mathrm{s}}$ \\
\hline \multirow[t]{3}{*}{ IPR } & TO & $204.43( \pm 36.47)$ & 21 & $201.78( \pm 33.84)$ & \multirow[t]{3}{*}{27} & $p_{\text {time }}$ * \\
\hline & T1 & $215.48(+38.71)$ & & $217.78( \pm 54.15)$ & & $P_{\text {group n.s. }}$ \\
\hline & & & & & & $p_{\text {time }} \mathrm{x}_{\text {group }}{ }^{\mathrm{n} . \mathrm{s}}$ \\
\hline \multirow[t]{3}{*}{ MaCs } & TO & $14.39( \pm 9.81)$ & 23 & $14.59( \pm 6.69)$ & \multirow[t]{3}{*}{27} & 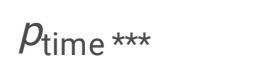 \\
\hline & $\mathrm{T} 1$ & $8.57( \pm 5.71)$ & & $8.96( \pm 8.04)$ & & \\
\hline & & & & & & $p_{\text {time }} \mathrm{x}_{\text {group }}{ }^{\mathrm{n} . \mathrm{s}}$ \\
\hline \multirow{2}{*}{$\begin{array}{l}\text { SCL } 90 \mathrm{R} \\
\text { Depression Score }\end{array}$} & TO & $58.14( \pm 9.09)$ & 21 & $62.70( \pm 10.52)$ & \multirow[t]{2}{*}{27} & $p_{\text {time }}{ }^{* \star *}$ \\
\hline & & & & & & $p_{\text {group n.s. }}$ \\
\hline \multicolumn{7}{|c|}{$\begin{array}{l}\text { Data displays means and standard deviations; } \mathrm{BDI}=\text { Becks Depression Inventory-II, MaCs= } \\
\text { Mannheimer Craving Scale, IPR= Inventory of personal resources, HAMD = Hamilton Depression } \\
\text { Rating Scale, BDI-II= Becks Depression Inventory-II; SCL= Symptom Checklist; } p_{\text {time }} \text { effect of time, }\end{array}$} \\
\hline \multicolumn{7}{|c|}{$p_{\text {group }}$ group effect, $p_{\text {time }}{ }_{\text {group }}$ interaction effect; ${ }^{*} p<0.05 * * x \leq 0.001$ n.s. $=$ not significant } \\
\hline
\end{tabular}


Interestingly, the present study revealed a trend (although not statistically significant) towards longer treatment retention of approximately 20 days in the methamphetamine group, which may indicate that methamphetamine users perhaps showed a greater benefit from the investigated treatment in terms of treatment retention or a higher need for treatment. However, with regards to all other treatment outcome measures, we did not find any interaction effects, which suggests that both groups overall benefited from treatment in a similar way. For example, both groups showed a reduction of craving, depression scores and overall psychiatric burden (measured by SCL-90R) and an improvement in working speed and working accuracy as well as an increase of psychosocial resources at the end of the treatment compared to the beginning. Therefore, it can be concluded that a current "treatment as usual" inpatient addiction program is helpful for methamphetamine users and users of other substances and that both user groups do not differ from each other in their response to the treatment.

Nevertheless, our study did reveal differences between methamphetamine users and other substance users, for example with respect to cognitive function. As we hypothesized, methamphetamine users had significantly lower baseline intelligence quotient, poorer working speed and lower working accuracy compared to users of other drugs. This finding underlines results from other studies indicating that methamphetamine use can reduce several cognitive functions ${ }^{8,9}$. However, school education was lower in the Methamphetamine-group, raising the question of whether impaired cognitive abilities in the Methamphetamine-group are a reason for or rather a consequence of methamphetamine use. Unfortunately, there are no longitudinal data to further explore this point. Furthermore, the performance of the Methamphetamine user group was still in the average range, when applying the test norms (t-values) and we had no matched control group without drug users to clarify the differences between both groups. Interestingly- and contrary to our assumptions- higher scores in working accuracy at baseline were associated with a higher likelihood for treatment drop-out. Other studies that have examined ADHD patients have found lower accuracy scores as significant predictors of drop out and mild cognitive deficits as a risk factor for treatment discontinuation, which is in contrast to the results of this study ${ }^{13}$. Furthermore, we did not find an effect of working speed and IQ on treatment retention, which makes it difficult to generalize the impact of poorer or better cognitive performance on treatment drop-out.

Again, as assumed, Methamphetamine-patients had a higher rate of comorbid anxiety and somatoform disorders. But contrary to this result, OS- group participants showed a higher rate of psychotic disorders and there were no differences between both groups in terms of other comorbidities. Therefore, different substance use patterns may be associated with different comorbidities, but this does not seem to affect treatment outcome. Future research is needed to clarify, if our results can be observed in other samples as well.

Another unexpected result was the negative association between neuroticism and treatment drop-out. The higher the score for neuroticism, the lower the odds of treatment drop-out. Other studies conclude, contrary to our results, that emotional instability and high neuroticism scores are risk factors for relapse at least in alcohol users ${ }^{14}$. Treatment dropouts in a program for cocaine addiction showed a higher score on histrionic and antisocial scales compared to completers ${ }^{15}$. Since it can be assumed that histrionic as 
well as antisocial personality traits tend to be associated with higher neuroticism, this result is also not consistent with our finding. We are not aware of any studies that specifically examined neuroticism as a predictor of addiction treatment dropout.

Our study has several limitations. For example, we did not correct the analyses for multiple testing, as this study was designed to generate hypotheses for future research on possible differences between Methamphetamine- and OS patients.

Furthermore, in the group that used other substances, amphetamine use was not an exclusion criterion. Even though the two substances are very similar, it has been suggested that methamphetamine has a stronger effect on the dopamine transporter mediated cell physiology than maphetamine and therefore leading to a higher addictive potential ${ }^{16}$.

Also the illustrated treatment effects are limited to the sample of treatment completers. Regarding the therapeutic effects of the drop-out group, there was no available data for T1, and therefore the treatment effects for the drop-out sample remain unclear. Especially, we did not gain enough information about those patients, who stopped treatment at their own request and therefore dropped out of study. The present study showed that the average time patients spend in treatment before they dropped out is still quite high (around three months). It remains unclear why they did not want to continue the treatment after already investing a lot of time and effort into it. Multiple investigations covering the whole treatment process including the monitoring of treatment alliance can help to gain information on later drop-outs. For example future research may clarify this point by conducting monthly or even weekly surveys on craving, treatment satisfaction and therapeutic relationship, since the latter factors are also known to influence treatment adherence or termination ${ }^{17-19}$.

\section{Conclusions}

There are differences between methamphetamine users and users of other drugs, but not with regard to the effectiveness of a six-months inpatient addiction treatment. Both groups showed a reduction in psychiatric symptoms over time and improved cognitive function after treatment compared to treatment begin.

Methamphetamine users therefore seem to benefit from existing, stimulant nonspecific treatment options in a similar way than other drug users do.

\section{Methods}

Participants and treatment program

All participants were inpatients at a hospital specialized for treatment of substance use disorders (MEDIAN Klinik Mecklenburg) and were recruited by psychologists and physicians during the first two to four weeks after admission. Participation was voluntary and not required for receiving treatment. The 
treatment was set up for six months and the interventions were applied as individual and group therapy, while the main focus was on group sessions (five times per week). Table 1 shows details about the treatment concept. Main treatment goals were the analysis of triggers for substance use and the development of new behavioral strategies for coping with craving and other substance related problems. The two-week initial phase aimed at completion of diagnostics, establishment of self-reflection and motivational support and finally defining therapy goals. During the twenty-two-week core treatment phase, interventions as for example psychoeducation, situation and trigger analyses, mindfulness strategies and assertiveness training were applied. The last two weeks focused on relapse prevention and networking for further outpatient treatment. For further details see also Soyka et al. ${ }^{20}$.

Inclusion criteria were a history of methamphetamine abuse or addiction (meeting the respective ICD-10 criteria) for the primary methamphetamine user group and a history of abuse or dependence of other substances for the other substances group (OS group). Because polydrug use is very common ${ }^{21}$ Methamphetamine-group participants were included when having a history of previous use of other substances, but methamphetamine had to be the primary drug of abuse and the reason for admission to treatment.

Minimum age was 18 years. Exclusion criteria were acute psychotic symptoms, intoxication on test days and insufficient comprehension of study materials or procedure. The study was performed according to the Declaration of Helsinki. Informed written consent was obtained from all participants after a complete and extensive description of the study protocol. The study protocol was approved by the Ethics Committee of the Ludwig-Maximilians-University of Munich, Germany (Project number: 422-16).

All participants were financially reimbursed with 15 Euro after completion of assessments. Routine urine samples and breath alcohol tests were collected to verify use of any substances. These tests were part of the usual hospital practice and were conducted by the clinic staff on a sample basis and in case of suspected substance use.

\section{Study Design}

The observational longitudinal study was designed to capture within and between group differences at two time points: "TO" Baseline at the beginning of treatment and " $\mathrm{T} 1$ " at the end of treatment, after approximately 24 weeks. The T1 assessment took place during the last 3 weeks before discharge and the exact time point varied individually. Both surveys were conducted by trained staff and took place in the MEDIAN clinic Mecklenburg. Data were collected between November 2016 and June 2018 for the Methamphetamine-group and between June 2018 and February 2019 for the OS-group.

\section{Outcome Measures and Instruments}

The main outcome of interest was the completion of treatment as scheduled (regular discharge). Individuals stopping treatment prematurely (at own request or as a disciplinary decision) were defined as 
dropouts. A positive urine test result was classified as a non-reported relapse, which led to a disciplinary dismissal.

Further outcomes of interest were differences between Methamphetamine- and OS-group and between time points T0 and T1. These differences include craving, cognitive functioning, psychosocial resources, depression and other psychiatric symptoms, as well as personality traits (only measured at baseline). Table 2 displays the used instruments at the respective assessment.

\section{Statistical Analyses}

Continuous variables were summarized by their mean $(\mathrm{m})$ and standard deviation (SD), categorical variables by absolute $(\mathrm{n})$ and relative frequencies (\%). Group comparisons were performed using chi $^{2}$ - test (for categorial variables, or in case of small cell numbers, Fisher's exact test) and t-test (continuous variables). Multiple mixed ANOVAs were calculated to compare mean differences between substance groups taking into account both time points (T0 and T1). Since t-tests and ANOVAs are regarded as robust statistical procedures, both methods were also used for variables potentially deviating from the normality assumption. Univariable logistic regression models were applied to investigate the effect of independent factors on treatment drop-out. Odds ratios (OR) are reported together with their $95 \%$ confidence intervals $(\mathrm{Cl})$. The significance level was set at $\mathrm{p}=.05$ and no $p$ value adjustment for multiple testing was applied in this explorative study. All statistical analyses were conducted in SPSS Version 24.

\section{Declarations}

\section{Funding:}

Part of the study was funded by the German Federal Ministry of health.

\section{Competing interests:}

The authors declare no competing interests.

\section{Data Availability Statement:}

Data are available on request.

\section{Ethics declarations:}

Ethics approval was made by the ethic committee of LMU Munich (Project number: 422-16)

\section{Author contributions:}

G.F., G.K. and M.S. designed the study. N.B., L.P. L.H., M.R., M.S-J., and W.H. performed study experiments. A.K.M. did the statistical analyses. F.K. wrote the manuscript. D.K. and S.N. contributed to writing and critical revisions. All authors read and approved the final manuscript. 


\section{References}

1. World Health Organization. World Drug Report 2020. United Nations publication Sales No.

E.20.XI.6. (2020).

2. World Health Organization. World Drug Report 2019. United Nations publication Sales No. E, 19. (2019).

3. Hamdorf, M., Susemihl, I., Schacht-Jablonowsky, M. Katamneseergebnisse der Entwöhnungsbehandlung bei apmhetaminabhängigen Patienten. Sucht Aktuell 2015 2: 43-46 (2015).

4. Die Drogenbeauftragte, B. f. r. G. B., Bundesärztekammer (BÄK), Deutsche Gesellchaft für Psychiatrie und Psychotherapie, Psychosomatik und Nervenheilkunde (DGPPN). . S3-Leitlinie "Methamphetaminbezogene Störungen" Leitlinienreport, 1. Auflage. Version 1. (2016).

5. Hoffmann, L. et al. Improving Rehabilitative Care of Methamphetamine Users in Germany: The Expert's Perspective. Qualitative health research 29, 248-259, doi:10.1177/1049732318792504 (2019).

6. Jones, C. M., Compton, W. M. \& Mustaquim, D. Patterns and Characteristics of Methamphetamine Use Among Adults - United States, 2015-2018. MMWR. Morbidity and mortality weekly report 69, 317323, doi:10.15585/mmwr.mm6912a1 (2020).

7. Barr, A. M. et al. The need for speed: an update on methamphetamine addiction. Journal of psychiatry \& neuroscience: JPN 31, 301-313 (2006).

8. Potvin, S. et al. Cognitive deficits in individuals with methamphetamine use disorder: A metaanalysis. Addictive behaviors 80, 154-160, doi:10.1016/j.addbeh.2018.01.021 (2018).

9. Proebstl, L., Kamp, F., Koller, G. \& Soyka, M. Cognitive Deficits in Methamphetamine Users: How Strong is The Evidence? Pharmacopsychiatry 51, 243-250, doi:10.1055/s-0043-123471 (2018).

10. Bernhardt, N. et al. Neurocognitive Dysfunctions and Their Therapeutic Modulation in Patients With Methamphetamine Dependence: A Pilot Study. Frontiers in psychiatry 11, 581, doi:10.3389/fpsyt.2020.00581 (2020).

11. Jalali, A., Shabrandi, B., Jalali, R. \& Salari, N. Methamphetamine Abusers' Personality Traits and its Relational with Spiritual Well-being and Perceived Social Support. Current drug research reviews 11, 44-50, doi:10.2174/1874473711666181017121256 (2019).

12. Kamp, F. et al. Effectiveness of methamphetamine abuse treatment: Predictors of treatment completion and comparison of two residential treatment programs. Drug and alcohol dependence 201, 8-15, doi:10.1016/j.drugalcdep.2019.04.010 (2019).

13. van Emmerik-van Oortmerssen, K. et al. Prediction of drop-out and outcome in integrated cognitive behavioral therapy for ADHD and SUD: Results from a randomized clinical trial. Addictive behaviors 103, 106228, doi:10.1016/j.addbeh.2019.106228 (2020).

14. Bottlender, M. \& Soyka, M. Impact of different personality dimensions (NEO Five-Factor Inventory) on the outcome of alcohol-dependent patients 6 and 12 months after treatment. Psychiatry research 
136, 61-67, doi:10.1016/j.psychres.2004.07.013 (2005).

15. Fernandez-Montalvo, J., López-Goñi, J. J. . Comparison of completers and dropouts in psychological treatment for cocaine addiction. . Addiction Research \& Theory, 18(4), 433-44 (2010).

16. Goodwin, J. S. et al. Amphetamine and methamphetamine differentially affect dopamine transporters in vitro and in vivo. The Journal of biological chemistry 284, 2978-2989, doi:10.1074/jbc.M805298200 (2009).

17. Meier, P. S., Donmall, M. C., McElduff, P., Barrowclough, C. \& Heller, R. F. The role of the early therapeutic alliance in predicting drug treatment dropout. Drug and alcohol dependence 83, 57-64, doi:10.1016/j.drugalcdep.2005.10.010 (2006).

18. Kelly, S. M., O'Grady, K. E., Brown, B. S., Mitchell, S. G. \& Schwartz, R. P. The role of patient satisfaction in methadone treatment. The American journal of drug and alcohol abuse 36, 150-154, doi:10.3109/00952991003736371 (2010).

19. Brorson, H. H., Ajo Arnevik, E., Rand-Hendriksen, K. \& Duckert, F. Drop-out from addiction treatment: a systematic review of risk factors. Clinical psychology review 33, 1010-1024, doi:10.1016/j.cpr.2013.07.007 (2013).

20. Soyka, M. et al. [Prevalence and Therapy of Crystal Methamphetamine Dependence]. Fortschritte der Neurologie-Psychiatrie 85, 92-99, doi:10.1055/s-0042-119862 (2017).

21. Crummy, E. A., O'Neal, T. J., Baskin, B. M. \& Ferguson, S. M. One Is Not Enough: Understanding and Modeling Polysubstance Use. Frontiers in neuroscience 14, 569, doi:10.3389/fnins.2020.00569 (2020).

22. Hautzinger, M., Keller, F., Kühner, C. Beck Depressions-Inventar (BDI-II). Hartcourt Test Services, Frankfurt (2006).

23. Wagner, M., Karner, T., . Manual Cognitrone. Schuhfried, Mödling. (2003).

24. German Society for Addiction Research and Therapy. Dokumentationsstandards III für die evaluation der Behandlung von Abhängigen: [Documentation standards III for the evaluation of addiction treatment]. SUCHT, pp. 3-94. (2001).

25. Hamilton, M. A rating scale for depression. Journal of neurology, neurosurgery, and psychiatry $23,56-$ 62, doi:10.1136/jnnp.23.1.56 (1960).

26. Küfner, H., Coenen, M., Indlekofer, W.,. PREDI - Psychosoziale Ressourcenorientierte Diagnostik: Ein Problem- Und Lösungsorientierter Ansatz, Version 3.0. Pabst Science Publ, Lengerich. Pabst Science Publ, Lengerich. (2006).

27. Nakovics, H., Diehl, A., Geiselhart, H. \& Mann, K. [Development and validation of an overall instrument to measure craving across multiple substances: the Mannheimer Craving Scale (MaCS)]. Psychiatrische Praxis 36, 72-78, doi:10.1055/s-2008-1067546 (2009).

28. Borkenau, P., Ostendorf, F., . NEO-FFI: NEO-Fünf-Faktoren-Inventar Nach Costa Und McCrae: Manual, 2nd ed. Hogrefe, Göttingen. (2008). 
29. Raven, J., Raven, C., Court, J.H., . Manual SPM Raven's Standard Progressive Matrices: . Version 33Revision 1. Schuhfried, Mödling (2016).

30. Wittchen, H.-U., Wunderlich, U., Gruschwitz, S., Zaudig, M., . SKID I. Strukturiertes Klinisches Interview Für DSM-IV. Achse I: Psychische Störungen. . Interviewheft Und Beurteilungsheft.: Eine Deutschsprachige, Erweiterte Bearbeitung Der Amerikanischen Originalversion Des SKID I. Hogrefe, Göttingen (1997).

31. Franke, G. H. SCL-90-R: Die Symptom-Checkliste von Derogatis: Deutsche Version. Beltz Test, Göttingen, pp. 21-28. (1995.).

32. Retz-Junginger, P. et al. [Wender Utah rating scale. The short-version for the assessment of the attention-deficit hyperactivity disorder in adults]. Der Nervenarzt 73, 830-838, doi:10.1007/s00115001-1215-x (2002).

\section{Figures}


A)

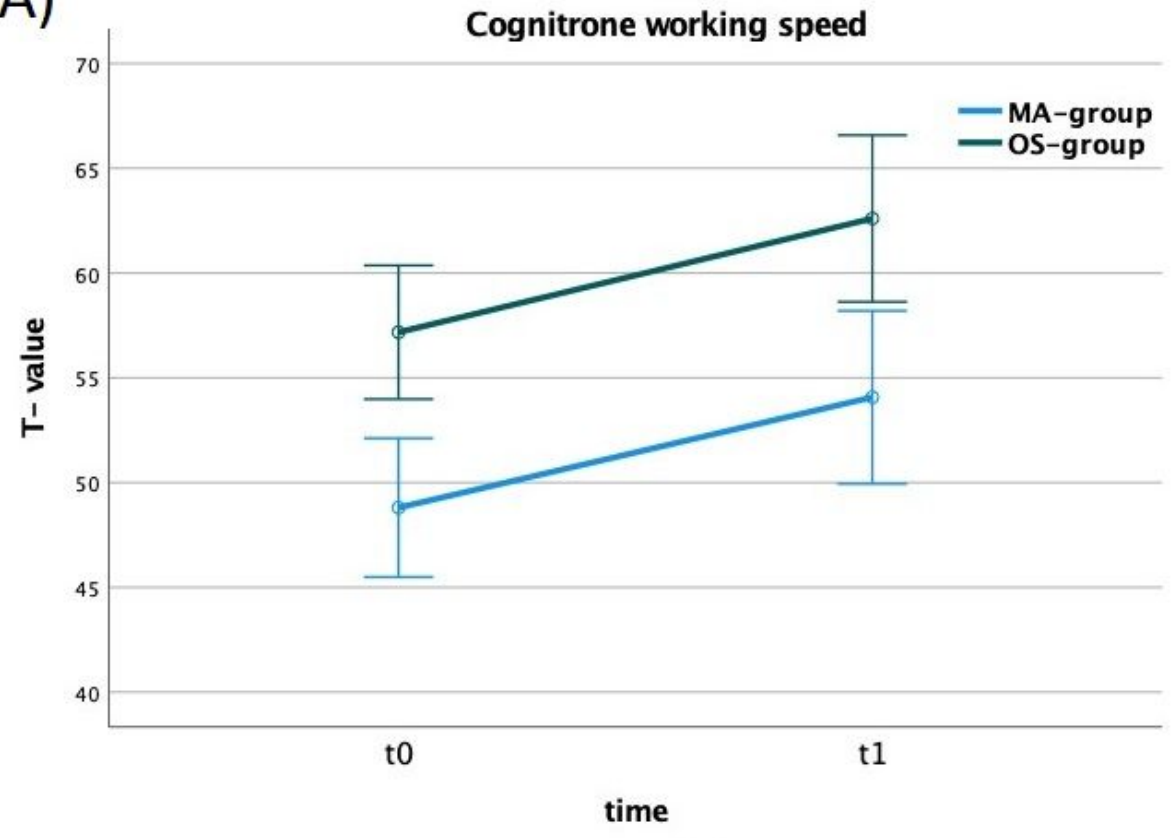

Fehlerbalken: $95 \% \mathrm{Cl}$

B)

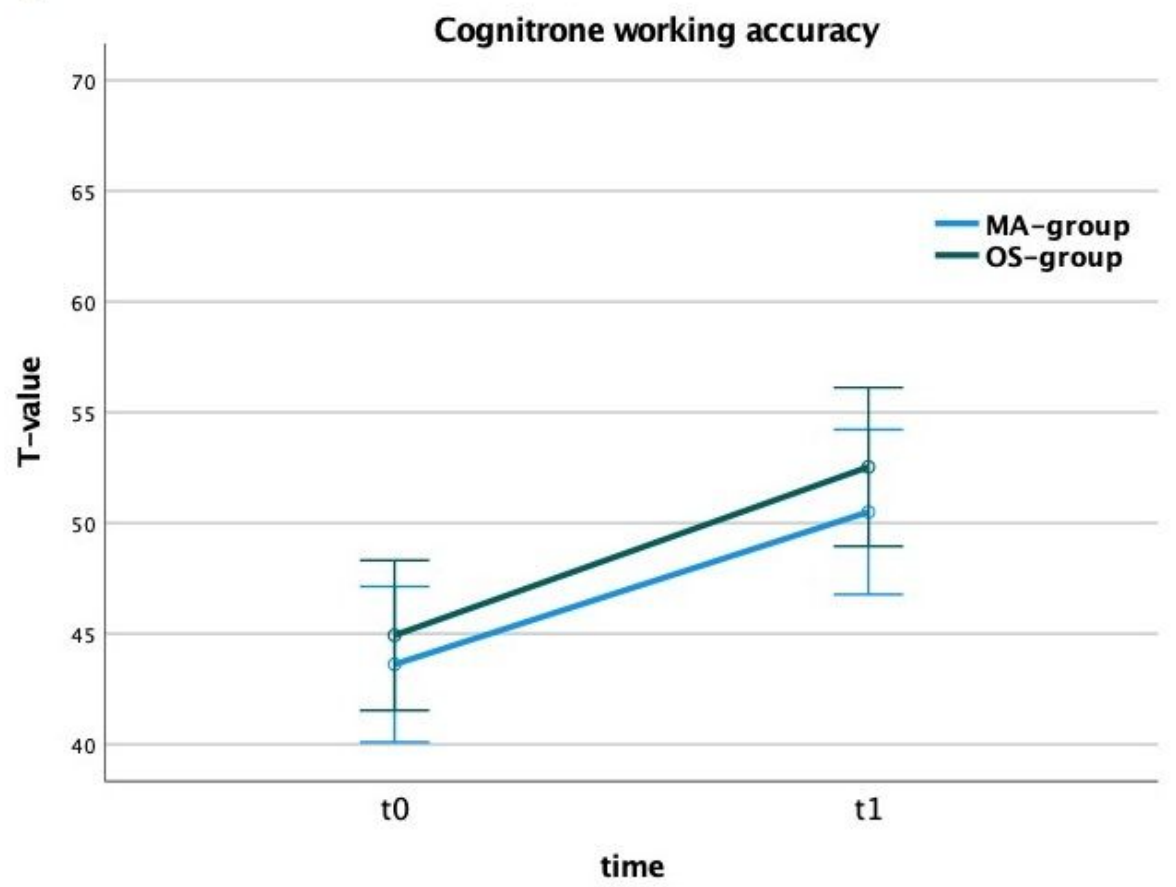

Figure 1

A) Working speed over time and between groups (error bars represent 95\% Cl) B) Working accuracy over time and between groups (error bars represent $95 \% \mathrm{Cl}$ ) legend: $\mathrm{MA}=$ methamphetamine, OS= other substances 


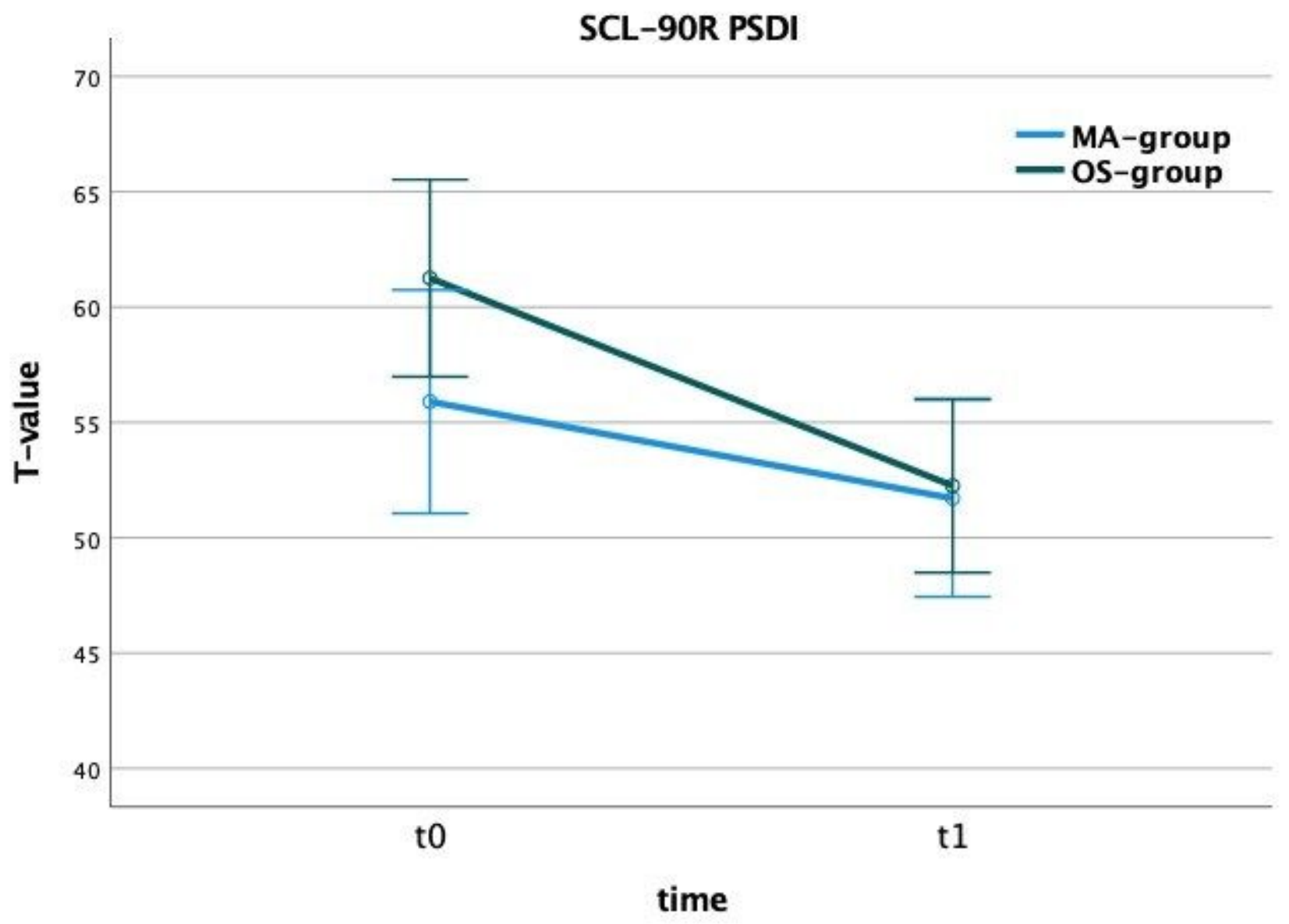

Fehlerbalken: $95 \% \mathrm{Cl}$

Figure 2

Positive Symptom Distress Index (SCL-90-R) over time and between groups (error bars represent 95\% $\mathrm{Cl}$ ) legend: $M A=$ methamphetamine, $O S=$ other substances 


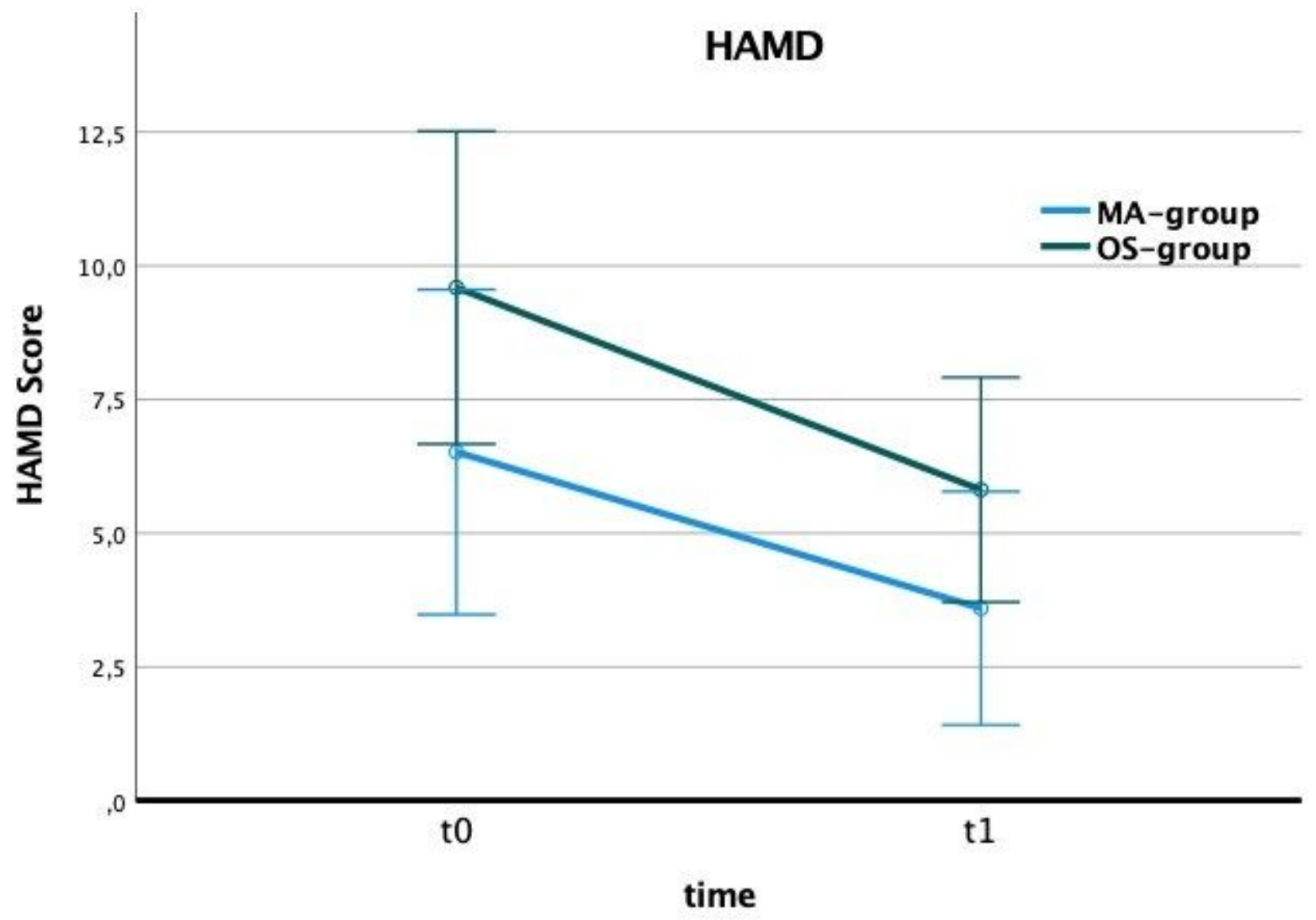

Fehlerbalken: $95 \% \mathrm{CI}$

\section{Figure 3}

HAMD scores over time and between groups (error bars represent $95 \% \mathrm{Cl}$ ) legend: $\mathrm{MA}=$ methamphetamine, OS= other substances, HAMD= Hamilton Depression Rating Scale 